\title{
Differences between the 7-spot and 2-spot ladybird beetles (Coccinellidae) in their toxic effects on a bird predator
}

\author{
NICOLA M. MARPLES, PAUL M. BRAKEFIELD** and RICHARD J. COWIE \\ Department of Zoology, University College Cardiff, Cardiff, Wales, and \\ *Section of Evolutionary Biology, Department of Population Biology, \\ University of Leiden, Leiden, The Netherlands
}

\begin{abstract}
Experiments with nestling blue tits Parus caeruleus L. examined the effects of feeding them 7-spot ladybird Coccinella septempunctata (L.), 2-spot ladybird Adalia bipunctata (L.) or controls Tenebrio sp.
\end{abstract}

2. A feeding rate of 51/37-spot ladybirds per day 'killed' nestlings within 2 days. Three of six nestlings fed at half this rate survived 4 days. In contrast, all experimental birds survived sixty-four 2-spot ladybirds fed over 4 days (equivalent by weight to the high 7-spot diet).

3. Nestlings fed 7-spot ladybirds also grew more slowly than birds fed 2 -spot ladybirds. The latter birds showed no difference in weight gain from the controls although they begged more strongly for food.

4. Cadavers of birds fed 7-spot ladybirds showed evidence of severe liver damage.

5. The results indicate a substantial difference between the ladybird species in their toxicity to nestling blue tits. They support the hypothesis that 2-spot ladybirds are largely-edible, polymorphic Batesian mimics of well-protected, monomorphic species such as the 7-spot ladybird.

Key words. Coccinellidae, Adalia bipunctata, Coccinella septempunctata, Parus caeruleus, toxicity, mimicry, selection, alkaloids, liver.

\section{Introduction}

Ladybird beetles with contrasting, aposematic colour patterns may be involved in mimetic resemblances (e.g. Muggleton, 1978). Brakefield (1985) suggests that different types of mimicry may be shown by different species. Monomorphic species within a community of

Correspondence: Professor Paul M. Brakefield, Section of Evolutionary Biology, Department of Biology, University of Leiden, Schelpenkade 14a, 2313 ZT Leiden, The Netherlands. ladybirds usually exhibit one of a restricted number of modal colour patterns such as red-withblack-spots or black-with-red-spots. They are thereby thought to benefit from membership of one of a small series of loose Müllerian mimicry rings. In contrast, polymorphic species exhibit several colour pattern forms, each of which may belong to a different mimicry ring. It was suggested that these variable species may be less well defended, chemically, than the monomorphic ones and that each form may gain some protection from bird predators through Batesian 
mimicry of the well defended Müllerian models (Brakefield, 1985). This paper describes a feeding experiment with nestling blue tits Parus caeruleus $\mathrm{L}$., which tests this prediction using two common species of ladybird: Coccinella septempunctata (L.) and Adalia bipunctata (L.).

The 7-spot ladybird C.septempunctata is one of the most abundant ladybirds in Western Europe. It is monomorphic with black spots on a bright red background. Information on the acceptability of C.septempunctata to avian predators is equivocal (see Brakefield, 1985). Feeding experiments have shown that captive tits, quail and starlings avoid eating them (Pasteels $\mathrm{et}$ al., 1973; Wiklund \& Järvi, 1982) but tree sparrows Passer montanus have been recorded feeding them to their young (Kristin, 1984, 1986).

The polymorphic 2-spot ladybird Adalia bipunctata is also common, the different forms being controlled by a co-allelic series at a single major gene locus. The form used in these experiments, typica, is bright red with two black spots and resembles species such as C.septempunctata. There are also shiny black forms with red spots which are similar in pattern to the monomorphic species of the genera Exochomus and Chilocorus. Again, records of bird predation on A.bipunctata are somewhat equivocal, but we have recorded them being fed to the nestlings of blue tits in suburban areas of Cardiff (R. J. Cowie and S. A. Hinsley, unpublished data). They are also taken by aerial feeders such as swifts Apus apus and house martins Delichon urbica (Owen, 1955; Muggleton, 1978).

Major components of the multiple chemical defence of ladybird beetles are bitter-tasting alkaloids and volatile pyrazines and quinolenes (Rothschild, 1961; Pasteels et al., 1973; Mueller et al., 1984; Rothschild et al., 1984; and see Brakefield, 1985). The alkaloids coccinelline and adaline occur in C.septempunctata and A.bipunctata, respectively (Pasteels et al., 1973), although little is known about their relative concentrations or toxicities. Intravenous injections of ladybird homogenate into the guinea-pig Cavia porcellus are certainly known to be fatal (Frazer \& Rothschild, 1960).

Evidence of Batesian mimicry in A.bipunctata may be important in understanding how the polymorphism is maintained since this form of mimicry would introduce frequency-dependent selection (Brakefield, 1985). Other factors which are known to influence the polymor- phism, such as thermal melanism and sexual selection (see Muggleton, 1978; Brakefield, 1987), are also unable to account for the colour patterns per se of the different forms.

\section{Materials and Methods}

\section{Birds}

Blue tit nestlings were taken from six nestboxes in a deciduous woodland in the Vale of Glamorgan, about 5 days after they hatched. At least four were left in each box to prevent desertion by the parents.

Sibling groups of four birds were placed in artificial nests of moss lined with tissue paper and housed in a constant temperature room at $25^{\circ} \mathrm{C}$ with a photoperiod of $18 \mathrm{~L}: 6 \mathrm{D}$. They were fed hourly over a $16 \mathrm{~h}$ period each day. Faecal sacs were collected on production and frozen. The birds were weighed every $4 \mathrm{~h}$ and the nest lining replaced.

\section{Food pellets .}

A blend of dog biscuit, dried meat, insectivore Sluis, seeds and grit was ground with boiled egg and vitamin syrup to prepare the standard food. Three types of treatment pellet were made from this mixture by adding a little water and homogenate of either adult 2-spot ladybird, adult 7-spot ladybird, or larval mealworm Tenebrio molitor L. The ladybirds were collected from post-hibernation populations in Cardiff (2-spots) or Oxford (7-spots). In each case batches of about twenty to thirty frozen insects were ground finely, then mixed with enough of the standard food and water so that each $0.03 \mathrm{~g}$ pellet included a single 2-spot ladybird of average size or its equivalent by weight (i.e. about one-third. of a 7-spot ladybird or mealworm). The pellets were stored frozen but thawed before use. A feeding trial using living, rather than frozen, 2-spot beetles to prepare pellets yielded no change in the results.

\section{Experimental design}

An initial trial involving eight birds was performed to develop the experimental design.

In the main experiment one bird in each nest was allocated randomly to each of four treatments and their beaks marked with different 
colours of waterproof ink. There was no difference in initial weight between the birds in each treatment $(F=0.49, \mathrm{df}=3,15, P=\mathrm{NS})$ although there was an initial difference between nests $(F=7.32, \mathrm{df}=5,15, P<0.01)$. The treatments were: 2 -spot high level=one 2 -spot ladybird pellet at each feed; 7-spot high level=one 7-spot ladybird pellet at each feed; 7-spot low level $=$ alternate 7 -spot ladybird and mealworm pellets; control diet $=$ one mealworm pellet at each feed.

At each feeding a treatment pellet was first placed on the tongue of a bird, using forceps. If the bird clearly tried to shake the pellet out, it was gently pushed down the throat. The bird was then offered three standard food pellets which it could eat or reject. With each pellet eaten a bird was given $0.5 \mathrm{ml}$ water from a syringe. Each bird was fed the appropriate diet for 4 days unless it began to refuse food completely and show signs of severe illness, at which point it was transferred to a control diet. During a full day on the treatment a bird received about 5 or $2 \frac{1}{2} 7$-spot ladybirds, 162 -spot ladybirds or 5 mealworms.

When the covering was taken off a nest before each feed, the presence or absence of begging by each bird and the rank height of their heads was recorded and converted to a 'begging score' such that failure to beg scored 0 and scores of 1-4 reflected increasing relative head heights. The number of pellets eaten by each individual and the number of faecal sacs they produced were also recorded at each feed.

The surviving nestlings were returned to their original nestboxes after the experiment. All nestlings in a sample of nestboxes checked later had fledged successfully.

\section{Results}

\section{Survival}

Nine of the twenty-four birds died or were taken off their treatment due to severe illness. This lethal effect was unexpected and subsequently birds showing similar severe symptoms were removed from the experiment to recover and the data treated as if they had died. Table 1 shows the pattern of survivorship. The nine 'deaths' were all of 7-spot treatments. Significantly more birds fed these treatments 'died' than those fed 2-spot or control pellets (Fisher exact test: $P<0.001)$.
TABLE 1. The number of birds surviving on each diet at the end of each day of the feeding experiment (initial number $=6$ for each diet).

\begin{tabular}{lllll}
\hline & Diet & & \\
\cline { 2 - 5 } & 7 -spot high & 7 -spot low & 2-spot & Control \\
\hline Day 1 & $5 \dagger$ & 5 & 6 & 6 \\
Day 2 & $2 \dagger \dagger$ & 5 & 6 & 6 \\
Day 3 & 0 & $3 \dagger$ & 6 & 6 \\
Day 4 & 0 & 3 & 6 & 6 \\
\hline
\end{tabular}

$\uparrow$ One bird died; $\uparrow \uparrow$ two birds died; other losses are due to birds being taken off the treatment after exhibiting severe symptoms (see text).

\section{Weight gain}

The curves for weight gain in individual birds are shown in Fig. 1. Each healthy bird showed a characteristic daily pattern of weight gain with an increase during the feeding period followed by a fall overnight.

Using the data for weight gain per day over the first 2 days only, a three-way analysis of variance excluding data for birds after death shows a highly significant treatment effect $(F=16.13$, $\mathrm{df}=3,31, P<0.001)$. Birds treated with 7 -spot pellets grew more slowly than other birds in a nest, although a few birds which died early in the experiment showed no apparent effect on growth rate (Fig. 1). The same ANOVA using data for the first 2 days indicates no nest or day effects (Nest: $F=0.91$, df $=5,31$; Day: $F=0.34$, $\mathrm{df}=1,31$, with $P=\mathrm{NS}$ in each case). However, a two-way analysis using birds from the four nests where none had died reveals a day effect, birds growing more slowly as they get older $(F=17.90$, $\mathrm{df}=1,24, P<0.001)$.

By the end of the experiment too many of the birds treated with 7-spot pellets had died for a full analysis of variance, but 2 -spot and control birds show no difference in growth rate $(F=0.21$, $\mathrm{df}=1,5, P=\mathrm{NS}$ ).

\section{Behavioural effects}

Fig. 2 shows mean daily values for the number of pellets taken, the number of faecal sacs produced and the begging score for birds on each treatment, plotted cumulatively over the duration of the experiment.

Analysis of these data by a Kruskall-Wallace test (which excludes data for birds after death) showed that on day 2 each behaviour differed 


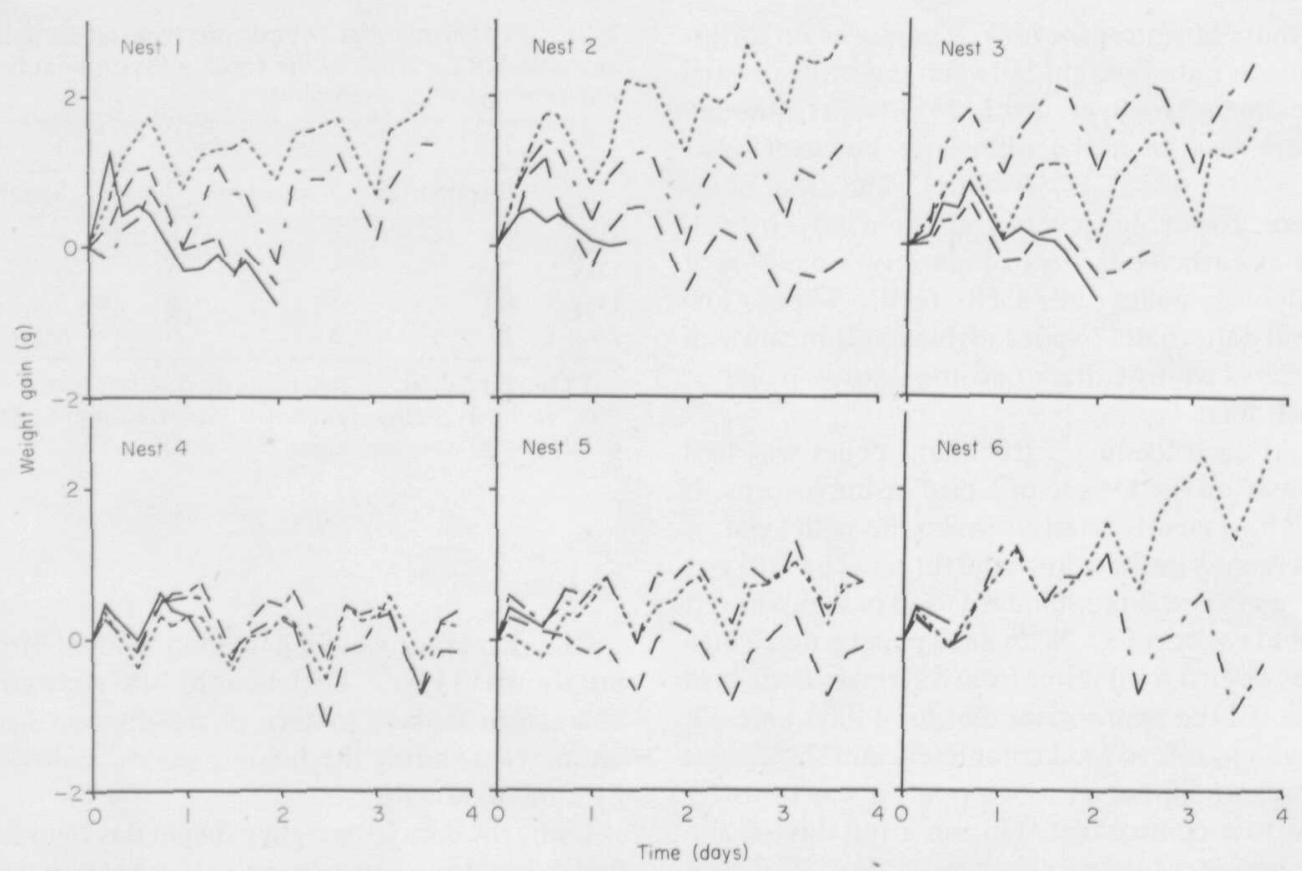

FIG. 1. Weight gain of the individual blue tit nestlings in each nest which were fed the following diets: $(-$, ) 7-spot ladybird high; $(--), 7$-spot ladybird low; $(---), 2$-spot ladybird; $(-\cdots)$, mealworm controls. Curves which end before 4 days indicate birds which died or were taken off the diet.

among treatments (pellets: $H=10.86, P<0.05$; begging, $\quad H=12.63, \quad P<0.01$; faecal sacs: $H=9.25, P<0.05$ with $\mathrm{df}=3$ in each case). Fig. 2 shows that 2 -spot treated birds consistently have higher mean cumulative scores than controls. The 7-spot birds gained higher scores than controls only for begging.

There was no difference between nests (pellets: $H=4.97$; begging: $H=2.01$; faecal sacs: $H=7.24$ with $\mathrm{df}=5$ and $P=\mathrm{NS}$ in each case). Only the defecation score was affected by age; older birds producing more sacs (pellets: $H=2.47, P=\mathrm{NS}$; begging $H=1.75, P=\mathrm{NS}$; faecal sacs: $H=9.40, P<0.05$ with $\mathrm{df}=3$ in each case).

\section{Discussion}

The distribution of deaths in the experiment shows that the 7-spot ladybird is much more toxic than the 2-spot ladybird for young blue tits. Deaths occurred only in birds on 7-spot ladybird diets. A pathologist's report on three cadavers indicated that their livers had suffered severe hepatocytic damage consistent with a toxic principle (no lesions or other effects were detected in the hearts). One bird which died after the experiment, having been fed only a 2 -spot ladybird diet, showed no such liver damage.

Widely different tolerances to the 7-spot ladybird diet were found, one bird died after eating the equivalent of $12 / 3$ beetles, while three survived 12 beetles. The mean tolerance was 7.13 beetles. Those birds taken off the 7-spot ladybird diets after severe symptoms began to behave and put on weight normally within a day.

The toxicity of 7-spot ladybirds is supported by the weight changes. The 7 -spot birds while on their treatment diets showed severely reduced growth rates compared with control birds, and surviving birds were noticeably less well developed in terms of size and feather growth than their wild siblings. In contrast, the birds fed 2-spot ladybirds showed no difference in growth rate over the experiment from control birds, nor did they appear to be developmentally behind these birds or their wild siblings.

The birds on the high level diet of 7-spot ladybirds often tried to reject the treatment pel- 

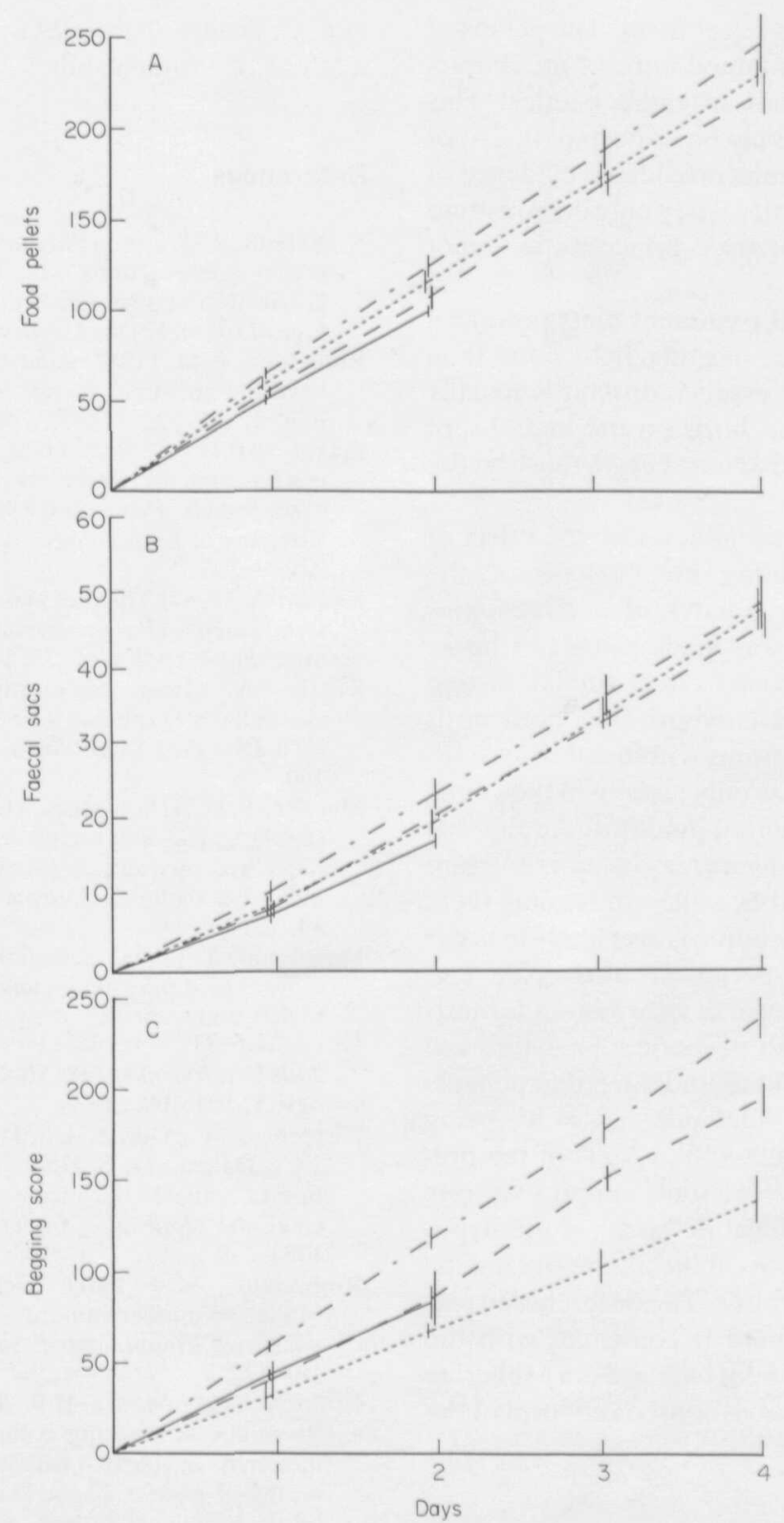

FIG. 2. Behaviour scores of birds on each treatment plotted cumulatively at daily intervals: A, mean number of pellets eaten; B, mean number of faecal sacs produced; C, mean begging score. Vertical ranges show standard errors. (- - , 7-spot high diet; (---), 7-spot low diet; (- - $)$, 2-spot diet; ( $\cdots . . .-$, control diet.

let while it was on the tongue, ejecting it with a shake of the head (there was no evidence of regurgitation). Those on a low level treatment never did this for the control pellets, but would eject or try to reject the 7-spot ladybird pellets.
This suggests that the bitter taste of 7-spot ladybirds to our senses was also detectable by the birds. Two-spot ladybirds also have a bitter taste for man although not as strong as 7-spots. However, birds fed on 2-spot ladybird pellets 
were not observed to reject them. The pellets of both ladybird diets retained some of the characteristic warning odour of these beetles. This defence component may be important in 2-spot ladybirds but our results provide no evidence of this for nestling blue tits. They only demonstrate a relative absence of toxic principles in 2-spot ladybirds.

The three ladybird treatment diets produced significantly stronger begging behaviour than the control diet. However, control birds actually ate more pellets than birds on the high 7 -spot ladybird diet and similar numbers to those on the other two diets.

A preliminary investigation into the effect of food pellets containing homogenate of the black-with-red-spots ladybird Exochomus quadripustulatus L. was made using two birds. This suggested a toxicity effect similar to that found for the 7-spot ladybird diet, both birds showing severe symptoms within 2 days.

This experiment has only examined the young stage of a single potential predator. Adult birds with fully developed livers may be more tolerant and thus take ladybirds while not feeding them to their nestlings. Variation is also likely to occur between different species of birds (see e.g. Kristin, 1984, 1986). An in vitro system for testing the relative toxicity of species of ladybird and extracts of their alkaloids and other components of their chemical defence is now being developed. Nevertheless the results of the present experiment provide some support for one aspect, that of chemical defence, of the hypothesis about differences in the nature of mimetic resemblances in ladybirds. The difference in toxicity demonstrated here is consistent with the suggestion that the 7-spot ladybird is a Müllerian model for the similarly-coloured red form of the 2-spot ladybird.

\section{Acknowledgments}

We thank Alison Mills for help with the experiment and the Glamorgan Naturalist's Trust and Nature Conservancy Council for their co-operation. Nestlings were taken and held under an
N.C.C. licence. Nicola Marples is supported by a N.E.R.C. Studentship.

\section{References}

Brakefield, P.M. (1985) Polymorphic Müllerian mimicry and interactions with thermal melanism in ladybirds and a soldier beetle: a hypothesis. Biological Journal of the Linnean Society, 26, 243-267.

Brakefield, P.M. (1987) Industrial melanism: Do we have the answers? Trends in Ecology and Evolution, 2, 117-122.

Frazer, J.F.D. \& Rothschild, M. (1960) Defence mechanisms in warningly coloured moths and other insects. Proceedings of the 11th International Congress of Entomology, Wien Verhandlungen B, 3, 249-256.

Kristin, A. (1984) The diet and trophic ecology of the tree sparrow (Passer montanus) in the Bratislava area. Folia Zoologica, 33, 143-157.

Kristin, A. (1986) Heteroptera, Coccinea, Coccinellidae a Syrphidae v potrave Passer montanus L. a Pica pica L. Biologia (Bratislava), 41, 143150.

Mueller, R.H., 'Thompson, M.E. \& Dipardo, R.M. (1984) Stereo- and regioselective total synthesis of the hydropyrido[2,1,6-de]quinolizine ladybug defensive alkaloids. Journal of Organic Chemistry, 49, 2217-2231.

Muggleton, J. (1978) Selection against the melanic morphs of Adalia bipunctata (two-spot ladybird): a review and some new data. Heredity, 40, 269-280.

Owen, D.F. (1955) Coleoptera taken by swifts (Apus apus L.). Journal of the Society of British Entomology, 5, 105-109.

Pasteels, J.M., Deroe, C., Tursch, B., Braekman, J.C., Daloze, D. \& Hootele, C. (1973) Distribution et activités des alcaloides défensifs des Coccinellidae. Journal of Insect Physiology, 19, 17711784

Rothschild, M. (1961) Defensive odours and Müllerian mimicry among insects. Transactions of the Royal Entomological Society of London, 113, 101-122.

Rothschild, M., Moore, B.P. \& Brown, W.V. (1984) Pyrazines as warning colour components in the monarch butterfly, Danaus plexippus, and in moths of genera Zygaena and Amata (Lepidoptera). Biological Journal of the Linnean Society, 23, 375-380.

Wiklund, C. \& Järvi, T. (1982) Survival of distasteful insects after being attacked by naive birds: a reappraisal of the theory of aposematic coloration evolving through individual selection. Evolution, 36, 998-1002.

Accepted 28 June 1988 